\title{
Persistence of multiple patterns and intraspecific polymorphism in multi-species Müllerian communities of net-winged beetles
}

\author{
Matej Bocek, Dominik Kusy, Michal Motyka and Ladislav Bocak *i]
}

\begin{abstract}
Background: In contrast to traditional models of purifying selection and a single aposematic signal in Müllerian complexes, some communities of unprofitable prey contain members with multiple aposematic patterns. Processes responsible for diversity in aposematic signaling are poorly understood and large multi-species communities are seldom considered.

Results: We analyzed the phylogeny and aposematic patterns of closely related Eniclases net-winged beetles in New Guinea using mtDNA and nextRAD data. We suggest three clades of closely related and incompletely reproductively isolated lineages, detail the extent of polymorphism among Eniclases, and categorize their low-contrast aposematic patterns. The warning signal of Eniclases consists of body shape and color, with ambiguous color perception under some circumstances, i.e., when resting on the undersides of leaves. Field observations suggest that perception of the aposematic signal is affected by beetle behavior and environmental conditions. Local communities containing Eniclases consisted of 7-85 metriorrhynchine species assigned to 3-10 colour patterns.

Conclusion: As a result, we suggest that under certain light conditions the aposematic colour signal is less apparent than the body shape in net-winged beetle communities. We document variable environmental factors in our study area and highly diverse multi-species communities of other net-winged beetles. Which implies dynamically changing community structure in space and time. Variable environmental conditions and diverse community composition are suggested to be favorable for the persistence of multiple aposematic patterns, imperfect mimics, and intraspecific polymorphism. Further research should identify the relative effect of these factors on purifying selection and the alleles which are responsible for phenotypic differences.
\end{abstract}

Keywords: Müllerian mimicry, NextRAD, mtDNA, Phylogeny, Lycidae, New Guinea

\section{Background}

Müllerian mimicry is among the best-studied examples of evolution, yet some theoretical predictions stand in contrast with observed mimetic communities in nature [1-3]. Although the number of exhibited patterns should be quickly reduced by natural selection [4-6], we commonly observe high variation in mimetic signals in a single place, or intraspecific polymorphism [7-10]. Evidently, some factors must diminish predator learning of the

\footnotetext{
* Correspondence: ladislav.bocak@upol.cz

Laboratory of Molecular Systematics, Faculty of Science, Palacky University, tr. 17. listopadu 50, 77146 Olomouc, Czech Republic
}

association between the visual warning signal and negative stimulus produced by unprofitable prey, thereby decreasing the effectiveness of purifying selection. Inquiry into potential factors has included differences in unpalatability (quasi-Batesian mimicry), the effects of multimodal signals, environmental conditions and community structure [11-13]. Non-adaptive genetic constraints may correlate with observed long-term persistence of a high number of distinct aposematic patterns in one place [7, 14], where such constraints include the inability to produce pigments necessary for advergence to the dominant, most effective pattern, or considerable delays in pigment production

(c) The Author(s). 2019 Open Access This article is distributed under the terms of the Creative Commons Attribution 4.0 International License (http://creativecommons.org/licenses/by/4.0/), which permits unrestricted use, distribution, and 
$[15,16]$. Mimics may differ in body structure such that only imperfect mimicry can be produced $[2,7,13]$. Differing interactions between genes and the environment among species may further prevent the dominance of a single signal in one community, for example, different melanization levels in response to a cold, humid climate in closely related Cautires beetles [17]. The origins and processes of imperfect mimicry have recently been reviewed [14], and in this study, we attempted to identify processes that may produce multi-pattern communities and counterbalance the hypothesized effects of selection for monomorphism in models of mimicry evolution [3, 4].

Net-winged beetles (Coleoptera: Lycidae) are considered Müllerian mimics, known for their unprofitability and aposematic coloration [18-20]. We focused on Eniclases, a trichaline genus of Metriorrhynchina from New Guinea [21, 22]. Having very closely related focal species, we expect that they do not differ substantially in the levels of their protection $[7,13,16]$. Patterns exhibited by trichalines are simple, combining two colors at most, namely, black and shades of yellow and orange in Eniclases. Unlike well-studied mimetic systems, few data are available regarding predation of Eniclases. The previous studies reported predators of net-winged beetles among birds, spiders, assassin bugs, and mantids [20].

Eniclases belongs to the clade of Australian Metriorrhynchina, which dominates lycid communities in New Guinea [23, 24]. More than 300 Metriorrhynchina have been described from this region, but preliminary analyses of molecular data suggest even greater species diversity. Most Metriorrhynchina are brightly colored, with patterns combining high-contrast red and black areas, metallic blue or green coloration, various patches and bands, and examples of tri-colored elytra (Figs. 1, 2, [25]). In total, 36 species of Eniclases are known and their relationships with Trichalus and related genera (hereafter, trichaline genera) have been established using molecular data and morphology [23, 24]. In New Guinea, trichalines such as Eniclases and Microtrichalus dominate mimetic systems at low elevations but are uncommon at elevations $>1500 \mathrm{~m}$ [24]. All net-winged beetles depend on humid forest, remaining mostly inactive under forest canopies. As a result, their dispersal propensity is low and no metriorrhynchine species have been simultaneously recorded from landmasses separated by open sea [17].

Currently, mimicry literature is biased to butterflies, the best studied model group (e.g., [4, 10, 25], with limited representations of mimicry in other animals (e.g., [26-28]). Therefore, we focused on New Guinean Müllerian beetle communities containing Eniclases and their metriorrhynchine co-mimics. Net-winged beetles are known as unprofitable and aposematic, yet have only recently been studied $[16,18,29]$ and the high diversity of aposematic patterns, and ecosystems in our study area provide a unique opportunity to investigate the pattern origins and composition of mimetic communities. We observed Eniclases in nature and investigated the New Guinean Eniclases and net-winged beetles communities to answer the following questions: Do the local communities contain species displaying multiple aposematic patterns or intraspecific polymorphism? Can the perception of aposematic signal differ under some conditions? How dissimilar are New Guinea net-winged beetle communities in species representation? We use RAD and mitochondrial DNA data to investigate if the phenotypic similarity is a result of relationships (aposematic signaling) or if the close similarity is encountered in unrelated species (mimicry hypothesis). Based on the investigation we try to estimate which factors potentially affect the evolution of aposematic patterns in Eniclases. Our study provides the first insight into the evolution of aposematic signaling in New Guinean net-winged beetles and we try to identify topics for further work.

\section{Results \\ Metriorrhynchina and community structure}

In total, we collected 1914 specimens of Metriorrhynchina beetles from seven localities in New Guinea (Figs. 3a, b). The majority of specimens were collected from aggregations, but some were collected from subsamples from different places (1009 spec., Table 1, Additional file 1: Tables S1, S7). All Eniclases and their co-mimics showed limited flying activity and all individuals in aggregations were collected from a few trees in an area $<1000 \mathrm{~m}^{2}$. Samples contained 95-433 individuals, 24-91 species total, and up to 6 species of Eniclases. Metriorrhynchina is highly diverse in the study area; altogether, 295 species were recorded, 50 trichaline and 12 Eniclases species. Most species were recorded from a single locality (231 species, Additional file 1: Table S6), whereas a minority were recorded from two (51 species), three (11 spp.) or four localities (2 spp.). The number of shared species among localities suggested similar species composition within the Wamena valley, i.e., Yiwika, Tikapura, Napua, and Bokondini (2000 m) (Fig. 4c). A group of low- to midelevation localities contained Sentani, Bokondini (1250 m), Dombomi, and Elelim. The number of aposematic patterns among all net-winged beetles varied between 3 and 10 at each locality, where only some of these patterns were exhibited by Eniclases (Table 1). Non-lycid co-mimics represented $<2 \%$ of individuals in each community and belonged to soldier beetles, true bugs, and moths (Fig. 1c, d). They are not discussed further.

Trichaline net-winged beetles represented a majority of three aggregations from a lowland foothill forest of the Cyclops mountains (275 m) (81.4\%, AGG1, sampling 


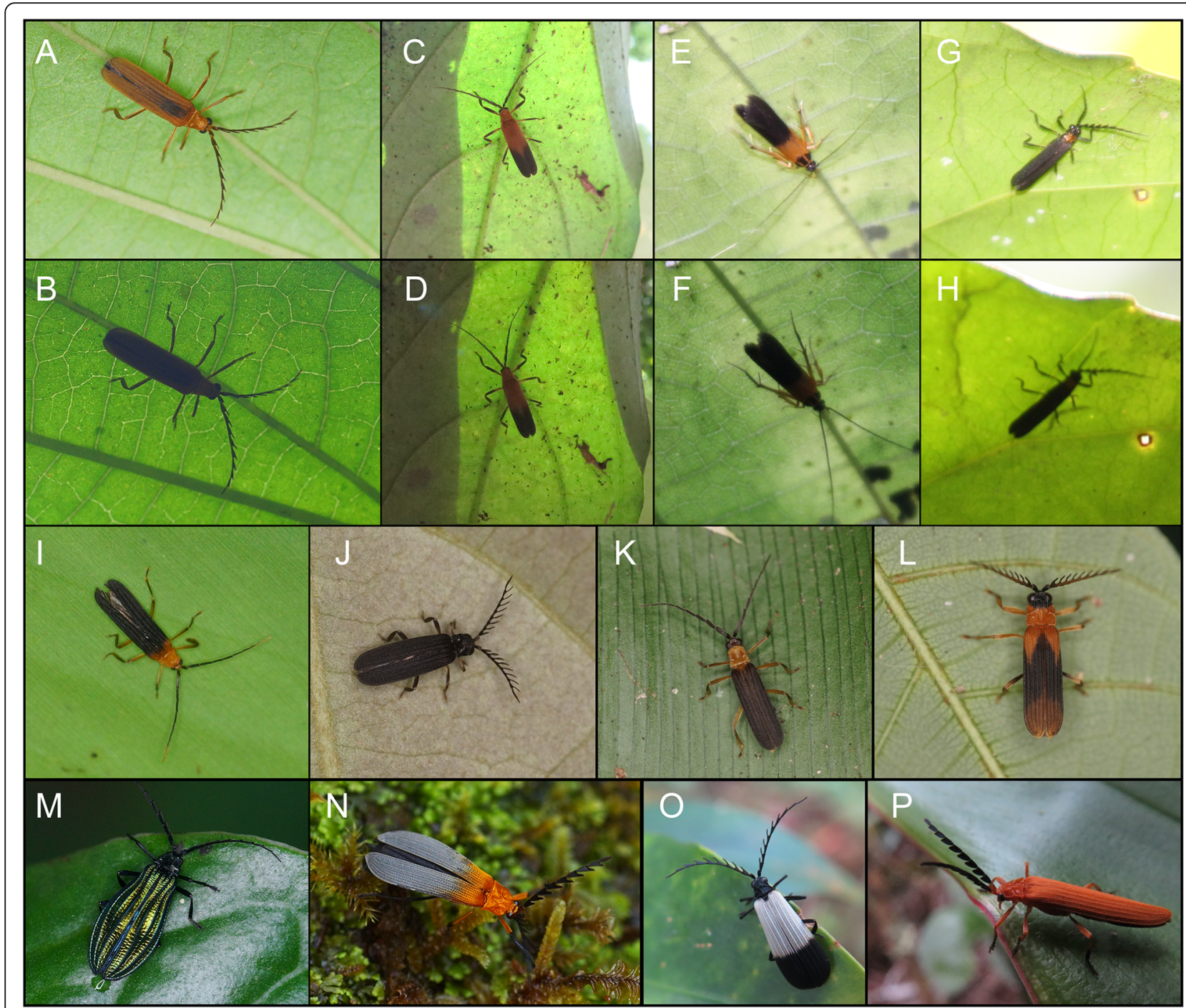

Fig. 1 Trichalini and their co-mimics as observed in nature. (a-h) - the examples of internal and external contrast of the signal of an individual depending on light conditions (the upper photo taken with flash); (a-b) - Eniclases sp.; (c-d) - Microtrichalus sp.; (e-f) - unidentified moth; (g-h) - Metriorrhynchus sp. Co-mimics of Eniclases: (i, $\mathbf{k})$ - Microtrichalus sp., (j, $\mathbf{l})$ - Metriorrhynchus sp. The representatives of further aposematic patterns recorded in the region: (m) - Diatrichalus aeneus Bourgeois, (n) - Cladophorus sp., (o-p) - Metriorrhynchus sp.

area of $\sim 500 \mathrm{~m}^{2}$ at a forest margin) and a low mountain forest of the Central Cordillera close to Bokondini $(1287 \mathrm{~m})$ (47.3 and $60.8 \%$ at AGG3 [300 $\mathrm{m}^{2}$ ] and AGG4 $\left[200 \mathrm{~m}^{2}\right]$, respectively). Further communities contained a wider spectrum of Metriorrhynchina and lower representation of trichalines. Samples from a lowland forest close to Elelim (560 m, AGG2) contained $36.3 \%$ trichalines, from an area of $\sim 1000 \mathrm{~m}^{2}$. In total, 763 Metriorrhynchina specimens were collected from higher-elevation mountain forests (Yiwika [2100 m], Bokondini [1700-2100 m], and Tikapura [2150 m]), places known to have a lower abundance of Eniclases (Table 1). Species turnover was high among localities, including those which were geographically close (Additional file 1: Tables S6 and S7).

\section{Presence of color patterns in net-winged beetles communities}

All patterns were shared by both sexes and shared patterns were identified in unrelated species (Fig. 4a). Intraspecific variation was identified in 5 of 14 species: Eniclases niger, E. similis, E. sp. B, E. variabilis, and E. elelimensis (Figs. 4a, Additional file 1: Figures S1-S4). Yellow-black and black patterns were distributed within lowlands and recorded up to $\sim 1300 \mathrm{~m}$, whereas pale yellow and pale yellow-dark patterns occurred at $>1500$ $\mathrm{m}$. The Dombomi fauna $(1150 \mathrm{~m})$ was dominated by a uniform black pattern.

We recorded several discrete mimetic phenotypes in a single place: 3-10 distinct patterns of Metriorrhynchina and 1-6 patterns of Eniclases (Table 1; Figs. 1, 2, 4a). 


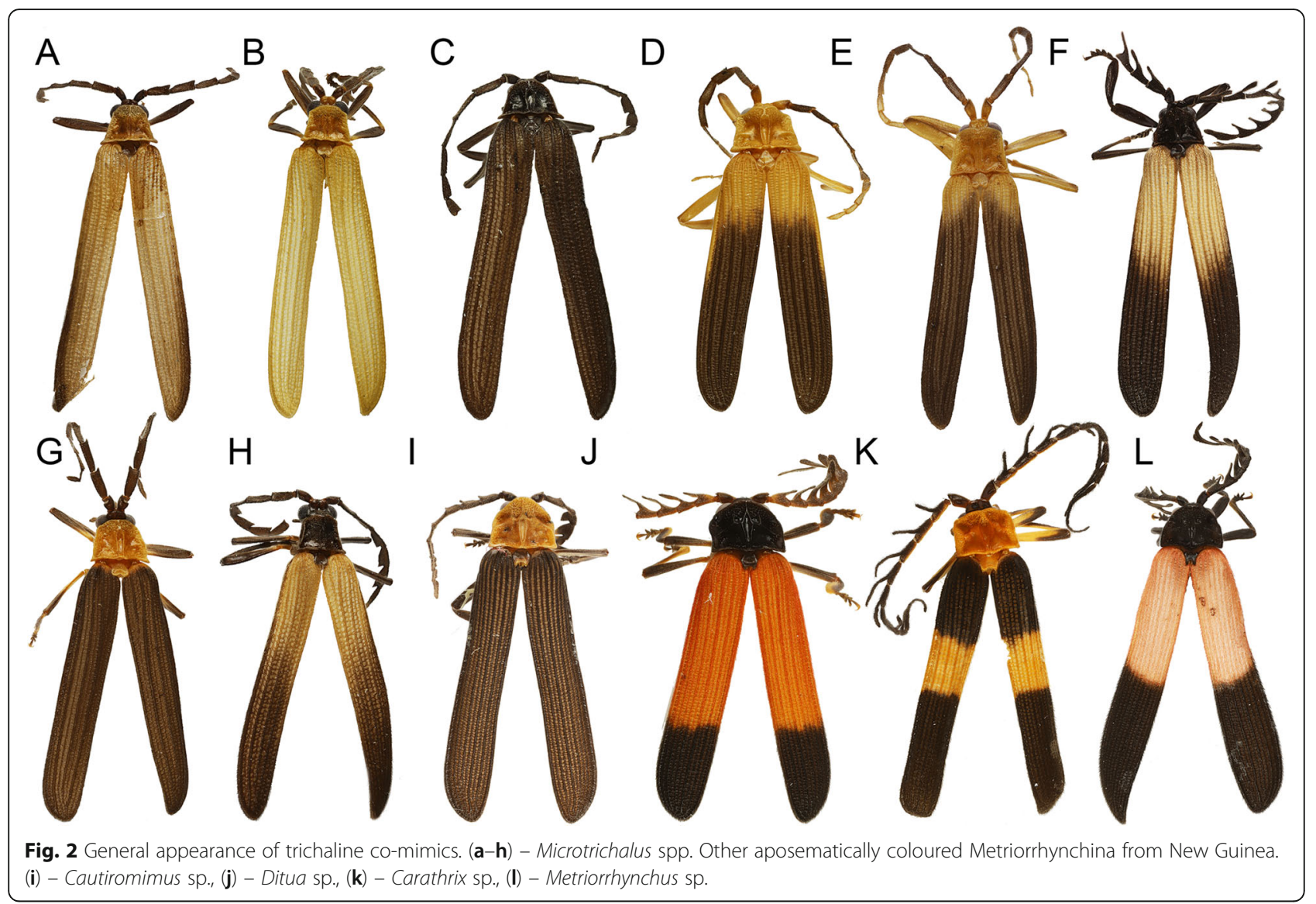

Color patterns in Eniclases were limited to pale yellow, bright yellow, and orange-yellow bright hues and dark brown to deep black on the upper-body parts. No Eniclases were grey, red- or metallic blue-colored, unlike many syntopically occurring Metriorrhynchina (e.g., Cautiromimus Fig. 2j, Carathrix, Porrostoma Fig. 1n, Diatrichalus Fig. 1m). Patterns in Eniclases closely resembled those of the related genus Microtrichalus from the same region (compare Microtrichalus sp. in Fig. 2c with $E$. apertus, E. pseudoapertus, E. niger the right specimen, and E. elelimensis the right specimen as they are shown in Fig. 4a. Further, compare Microtrichalus sp. in Fig. 2d with E. bicolor, E. similis the left specimen, and Eniclases sp. B the left specimen. Similarly, compare Microtrichalus sp. in Fig. $2 \mathrm{~g}$ with E. niger the right specimen, Eniclases sp. B the left specimen, and E. elelimensis

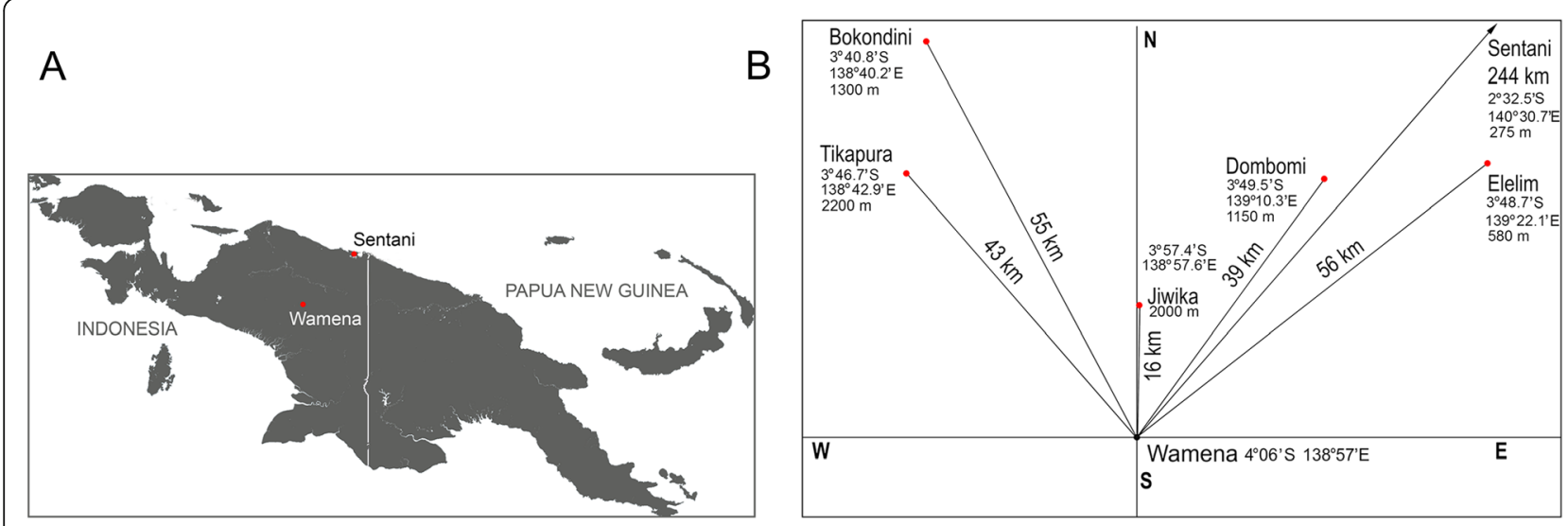

Fig. 3 (a) Map of New Guinea; (b) The relative geographic position of sampled localities, with coordinates and elevation above sea level 
Table 1 The characteristics of net-winged beetle alpha-diversity and the number of identified color patterns in each locality

\begin{tabular}{|c|c|c|c|c|c|c|c|c|c|c|c|c|c|c|}
\hline \multirow{3}{*}{$\begin{array}{l}\text { Locality, Altitude } \\
\text { Sentani } 275 \text { m }\end{array}$} & \multirow{3}{*}{$\begin{array}{l}\text { AGG } \\
1\end{array}$} & \multicolumn{6}{|c|}{ Number of individuals (n) } & \multicolumn{5}{|c|}{ Number of spp. (n) } & \multicolumn{2}{|c|}{ \# of patterns } \\
\hline & & \multirow{2}{*}{$\begin{array}{l}\text { Total } \\
414\end{array}$} & \multirow{2}{*}{$\begin{array}{l}\text { non-trich. } \\
77\end{array}$} & \multicolumn{2}{|c|}{ trichalines \% } & \multicolumn{2}{|c|}{ Enicl. \% } & \multirow{2}{*}{$\begin{array}{l}\text { Total } \\
26\end{array}$} & \multirow{2}{*}{$\begin{array}{l}\text { non- trich. } \\
14\end{array}$} & \multirow{2}{*}{$\begin{array}{l}\text { trich. } \\
12\end{array}$} & \multicolumn{2}{|c|}{ Eniclases \% } & \multirow{2}{*}{$\begin{array}{l}\text { Total } \\
7\end{array}$} & \multirow{2}{*}{$\begin{array}{l}\text { Enicl. } \\
4\end{array}$} \\
\hline & & & & 337 & 81.4 & 167 & 40.3 & & & & 5 & 19.2 & & \\
\hline Sentani, $360 \mathrm{~m}$ & - & 19 & 9 & 10 & 52.6 & 2 & 10.5 & 7 & 3 & 4 & 2 & 22.2 & 3 & 2 \\
\hline Elelim, $580 \mathrm{~m}$ & 2 & 234 & 149 & 85 & 36.3 & 20 & 8.5 & 85 & 67 & 18 & 6 & 7.1 & 10 & 6 \\
\hline Dombomi (1150) & - & 123 & 89 & 34 & 27.6 & 9 & 7.3 & 24 & 23 & 1 & 1 & 4.2 & 6 & 1 \\
\hline Bokondini (1250) & 3 & 110 & 36 & 74 & 67.3 & 36 & 32.7 & 18 & 9 & 9 & 2 & 11.1 & 4 & 2 \\
\hline Bokondini (1287) & 4 & 251 & 99 & 152 & 60.8 & 43 & 17.2 & 13 & 9 & 4 & 2 & 15.4 & 3 & 2 \\
\hline Bokondini (1800) & - & 297 & 171 & 126 & 42.4 & 4 & 1.3 & 47 & 44 & 3 & 2 & 4.3 & 9 & 2 \\
\hline Bokondini (2100) & - & 24 & 20 & 4 & 16.7 & 2 & 8.3 & 15 & 14 & 1 & 1 & 6.7 & 7 & 1 \\
\hline Tikapura (2170) & - & 201 & 173 & 28 & 14.0 & 7 & 3.5 & 53 & 39 & 14 & 1 & 1.9 & 8 & 1 \\
\hline Yiwika (2100) & - & 95 & 78 & 17 & 17.9 & 1 & 1.1 & 42 & 34 & 8 & 1 & 2.4 & 7 & 1 \\
\hline Napua (2300) & - & 146 & 138 & 8 & 5.5 & 0 & 0.0 & 48 & 44 & 4 & 0 & 0.0 & 8 & 0 \\
\hline
\end{tabular}

$\mathrm{n}$ - number of individuals, non-trich. - the genera if Metriorrhynchina except the trichalines; trichaline genera (trichalines) - the genera Diatrichalus,

Flabellotrichalus, Eniclases, Microtrichalus, Trichalus, and Lobatang. The numbers for Eniclases, are included always also under trichalines as a whole and then separately reported

the right specimen. All Eniclases are shown in Fig. 4a, at the terminal branches of the phylogram showing their relationships. The transition between bright and dark body parts was sometimes gradual (e.g., E. infuscatus, shown in Fig. 4a); in extreme cases, only the apices of elytra were lightly infuscated (E. tikapurensis, Fig. 4a), or high contrast was present ( $E$. variabilis, the left specimen in Fig. 4a).

\section{Phylogeny and genetic structure}

The nuclear RAD dataset (Wclust $=0.85, \operatorname{MinCov}=4$ ) encompassed 47,000 to 108,000 clusters of possible loci with a mean depth from 5.3 to 32, mainly owing to the low quality of some isolates. As discussed in Methods, we used a Wclust threshold of 0.85 to balance the maximum number of clusters recovered against the loss of individual heterozygosity. The number of clusters generated using a Wclust of 0.85 provided loci with the high heterozygosity level (Additional file 1: Figure S5). The topology produced by the analysis of the Wclust = 0.85 and MinCov $=4$ dataset is shown in Fig. 4A. maximum likelihood analyses of RAD and mtDNA datasets recovered a highly similar topology (Figs. 4a, b) and the highly similar topology was also recovered when data for individuals belonging to the same clade were separately filtered, a higher number of orthologous loci was identified, and de novo assembled. All analyses supported three clades of closely related species within Eniclases further designated as clades A, B, and C (Fig. 4a). Altogether, thirty datasets defined in Table 2 were analyzed using maximum likelihood approach and resulting trees are provided in the newick format in Additional file 2. Deeper splits were poorly supported and are not discussed. Information on numbers of SNPs, positions and loci is summarized in Table 2. Additionally, PCA analyses confirmed the clusters delimited using RAD-based phylogeny (Fig. 5a-c, Additional file 1: Figure S9). Based on the mtDNA mutation rates, the earliest splits within clades $\mathrm{A}, \mathrm{B}$, and $\mathrm{C}$ were estimated to $4.39,0.27$, and 1.81 mya, respectively (Fig. 4b). Alternative calibration approaches produced only slightly different estimations for critical splits (Additional file 1: Figure S8).

\section{Discussion}

Analyses of all data recovered the monophyly of the three clades relevant to this analysis, each consisting of two to five closely related Eniclases species (Figs. 4, 5). We identified the recent origin of most Eniclases species and mtDNA introgression, indicated by individuals with different nuclear but identical or highly similar mtDNA sequences (Figs. 4, 5). Our species delimitations are based on RAD analyses, as this extensive, genome-wide data can better resolve clusters of individuals with shared ancestry, particularly among closely related species and recently separated populations [30]. Results from sNMF and PCA analyses identified some genomes even with the different genetic structure within the RAD phylogeny-based species-rank entities (Additional file 1: Figures S10-S14) and collectively, the analyses suggested ongoing gene flow and that most species represent recently split lineages, typically within the last million years (Fig. 4b).

\section{Mimetic patterns in Eniclases}

The foundational premise of Müllerian mimicry holds that unprofitable prey benefit from convergence in warning signals [2]. The phylogeny of Eniclases showed that resemblance among various Eniclases is the product 


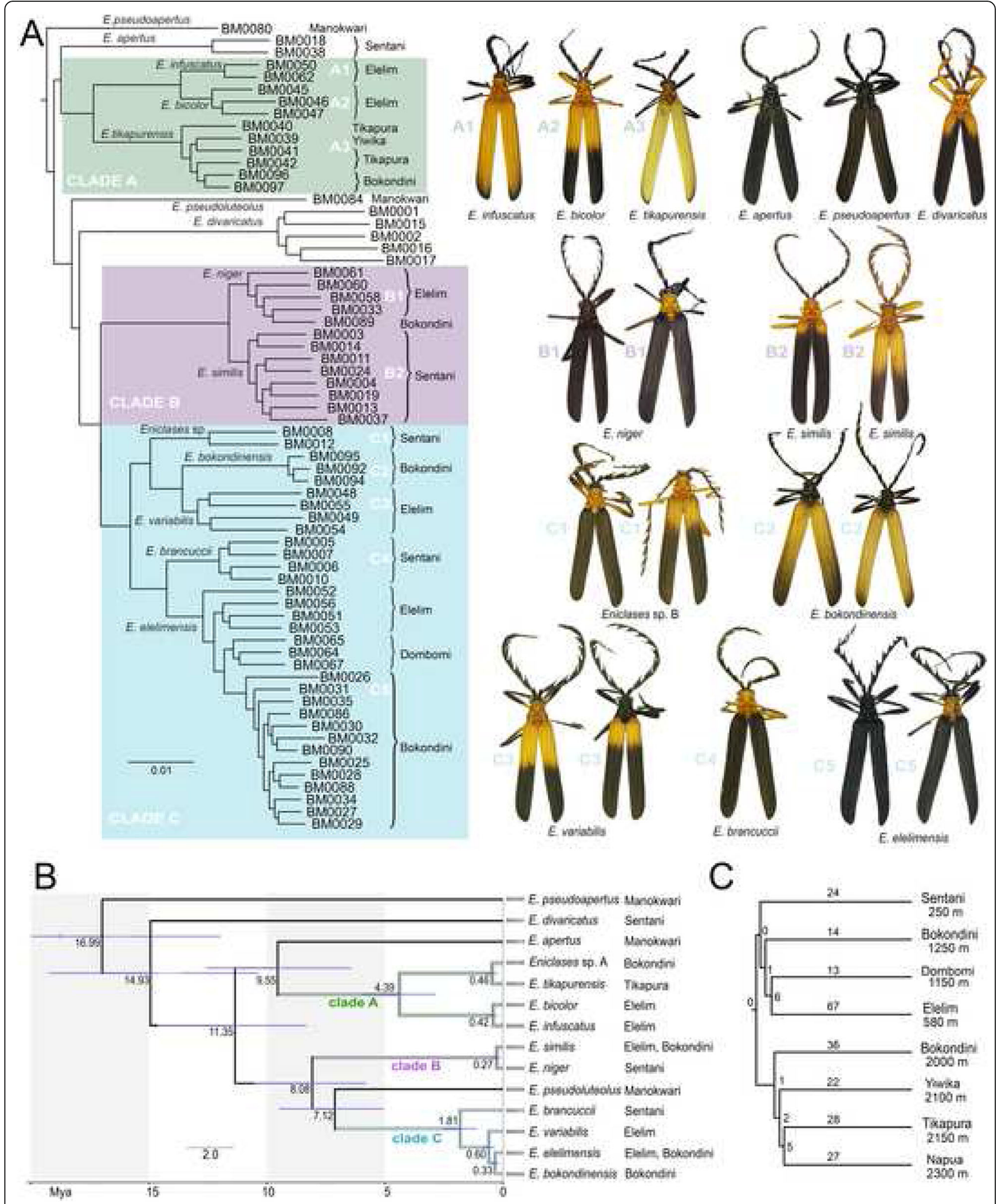

Fig. 4 (a) - RAD-based maximum likelihood topology with characteristic aposematic patterns for each putative species. The analyzed dataset contained $8.76 \times 10^{4}$ loci and $6.5 \times 10^{5} \mathrm{SNPs}$; all individuals included in the analysis are shown in Additional file 1: Tables S1-S4; (b) - Dated phylogenetic tree based on mutation rates of three mitochondrial fragments; (c) - Similarity of species composition. The numbers designate share and unique species, respectively 
Table 2 The characteristics of 66-sample RAD datasets produced under various Wclust and MinCov settings

\begin{tabular}{|c|c|c|c|c|c|c|c|}
\hline \multicolumn{2}{|c|}{ MinCov number/\% } & $4 / 7 \%$ & $8 / 12 \%$ & $16 / 24 \%$ & $33 / 50 \%$ & $48 / 73 \%$ & $60 / 91 \%$ \\
\hline \multicolumn{8}{|l|}{ Wclust } \\
\hline \multirow[t]{3}{*}{0.70} & number of SNPs & 407 & 127.3 & 24.4 & 2.56 & 0.54 & 0.05 \\
\hline & number of sites & 3299 & 900 & 164 & 19.3 & 4.15 & 0.44 \\
\hline & number of loci & 47.1 & 12.8 & 2.29 & 0.26 & 0.10 & 0.01 \\
\hline \multirow[t]{3}{*}{0.75} & number of SNPs & 481 & 157.1 & 31.7 & 3.70 & 1.01 & 0.16 \\
\hline & number of sites & 3906 & 109.7 & 205 & 26.7 & 7.41 & 1.12 \\
\hline & number of loci & 55.8 & 15.6 & 2.87 & 0.36 & 0.10 & 0.02 \\
\hline \multirow[t]{3}{*}{0.80} & number of SNPs & 565 & 194 & 40.7 & 4.97 & 1.45 & 0.25 \\
\hline & number of sites & 4748 & 1372 & 259 & 34.6 & 10.1 & 1.69 \\
\hline & number of loci & 67.8 & 19.54 & 3.64 & 0.48 & 0.14 & 0.02 \\
\hline \multirow[t]{3}{*}{0.85} & number of SNPs & 650 & 240 & 54.6 & 6.27 & 2.09 & 0.55 \\
\hline & number of sites & 6066 & 1813 & 356 & 44.8 & 15.3 & 3.79 \\
\hline & number of loci & 86.7 & 25.9 & 5.0 & 0.63 & 0.23 & 0.05 \\
\hline \multirow[t]{3}{*}{0.90} & number of SNPs & 622 & 241 & 59.3 & 7.57 & 2.60 & 0.69 \\
\hline & number of sites & 7548 & 2241 & 444 & 56.8 & 20.6 & 5.31 \\
\hline & number of loci & 108.0 & 32.1 & 6.33 & 0.80 & 0.29 & 0.08 \\
\hline
\end{tabular}

The numbers of SNPs, sites and loci are given in thousands

of parallel evolution rather than common ancestry (Fig. 4a). Our data support the Müllerian mimicry hypothesis by the noted sympatric occurrence of distantly related but similarly colored Metriorrhynchina with Eniclases (Figs. 1g, h-l, 2). Additionally, the detailed delimitation of species confirms the presence of intraspecific colour polymorphism in these Müllerian mimics with intraspecific forms resembling unrelated Eniclases and Microtrichalus species.

Aggregations of net-winged beetles in the field indicate that multiple species truly coexist in a single community and do not have a microhabitat-based mosaic distribution. Up to six Eniclases aposematic patterns were recorded within single localities in our small study area (Table 1; Fig. 3b) and additional patterns were displayed by closely related Metriorrhynchina (altogether up to 10 patterns in a single locality; Table 1). Unlike findings from other Müllerian mimetic systems [31], these observations suggest that a dominance effect on mimetic polymorphism stemming from microhabitat preference is improbable in Eniclases.

Coloration of Eniclases is limited to pale to bright yellow, yellowish-orange, and black, but these beetles display multiple distinct color forms with a putative signaling function (Figs. 4a, Additional file 1: Figures S1-S4). Dominant color patterns combine a bright-colored pronotum and elytral humeri with apically dark elytra. Higher contrast is represented by a steeper transition between bright and black parts of the elytra or pronotum. Three species in the study area are black, two of which are polymorphic with some individuals having a yellow pronotum (Fig. 4a).
These patterns dominate in all communities containing high representation of trichaline net-winged beetles, generally those $<1500 \mathrm{~m}$ in elevation. Additional patterns among high-elevation species are uncommon and include pale yellow or creamy white in combination with a black pronotum and elytral apex (Fig. 4a). Eniclases are never red, green, or metallic blue (Figs. 11-o, 2j-1) and never display three colors, unlike numerous sympatric Metriorrhynchina. It is possible that the absence of red pigment in Eniclases is genetically constrained. Earlier studies have shown that easily remembered, high-contrast patterns, e.g., a red-black combination, provide higher protection than lower contrast ones (e.g., [32, 33]. Relative to other net-winged beetles in the same communities, we consider color patterns in Eniclases as low contrast, and their effectiveness is likely further reduced by relatively high intraspecific variability, given that 5 of 12 species from Central New Guinea are polymorphic [15] (Fig. 4a, Additional file 1: Figures S1-S4).

Aposematic color patterns are controlled by selection $[1,2]$ and their distinctness depends on the ability of predators to discriminate among them and on the intensity of predation upon intermediate forms [34]. In contrast to the observed high signal variability, we recorded a distinct, fine-tuned warning signal in $E$. divaricatus and its co-mimics (E. similis, Trichalus sp., and Cautiromimus sp.) represented by characteristic bright-colored humeral patches (Fig. 4a). The specificity of brightly colored humeral patches versus whole humeri color might support the potential role of predators [35] but the present study design cannot 


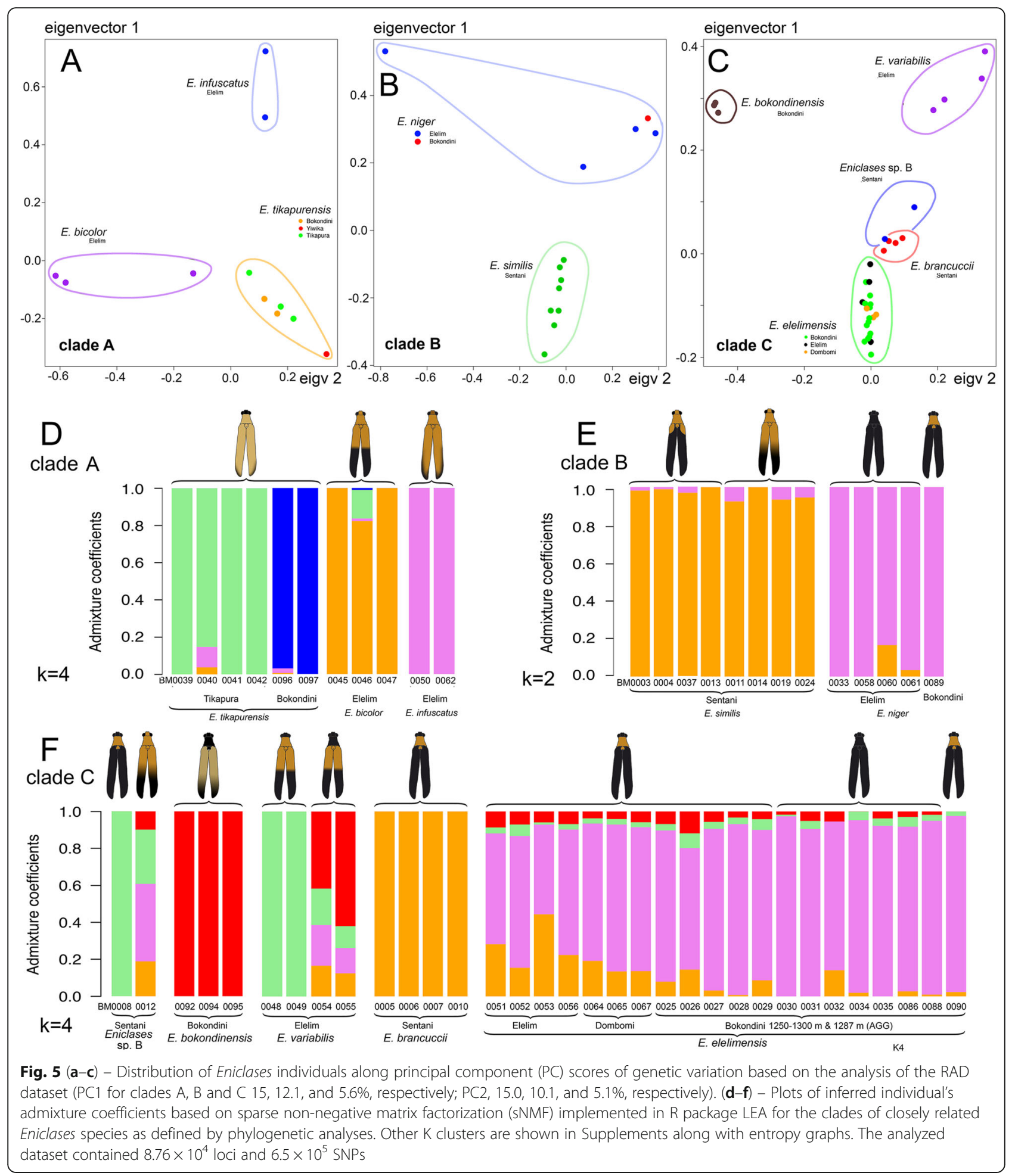

provide any experimental evidence. Nevertheless, the structure of Eniclases communities shows that under certain conditions, both polymorphism and high pattern similarity can persist within a multi-pattern Müllerian community.

\section{Behavior and signal perception}

Given that trichalines commonly occur in multispecies and multi-pattern aggregations (Table 1), predators encounter a spectrum of aposematic signals related to components such as body shape and colour 
[12, 36-38]. Further complexity is added to aposematic signaling by different perception of the signal in space and time.

A body shape and size signal are predominantly perceived when an individual sits on the underside of a translucent leaf (Fig. 1a-h). This perception depends on light intensity, microhabitat conditions, and season [15]. We observed that Eniclases prefer the undersides of leaves, as do other trichaline genera. We assume that convergent evolution has led to the observed morphological uniformity in body shape and size of $>100$ species of trichalines in New Guinea (Additional file 1: Figures S1-S4, Table S4).

Color-based component of signals include hue, uniform or bicolored upper bodies, color patch shape, and the level of contrast between body parts (Figs. 1, 2, 4a). Color is best detected under diffuse-light conditions under a dense forest canopy or when an individual is on upper leaf surfaces, but Eniclases and its co-mimics usually avoid upper leaf surfaces, unlike brightly colored lycids such as Porrostoma, Metriorrhynchus, and Cladophorus ([24], field observation). When color pattern is not readily observable, we can assume that the shape component of the signal is relatively stronger. Therefore, the further research is needed to clarify if selection for a shared color pattern might be relaxed. Penny et al. [8] showed the importance of relaxed selection in the origin of imperfect mimicry; we suggest that it may also increase the persistence of a greater number of color patterns in a community (Fig. 4a, Table 1).

Overall, we documented apparent convergence and/ or advergence to shared color patterns in distantly related species within Eniclases and in unrelated Microtrichalus (Figs.2, 4a; compare phenotypically similar and phylogenetically unrelated individuals as described above). Such similarity is usually caused by selection $[1,2,4-6]$, which was not studied in this project by experiments. Therefore, excluding similarity due to the common origin, we can speculate that observed similarity of these unpalatable and aposematically coloured beetles is a result of natural selection. In contrast with the Müllerian model which predicts strong selection against rare phenotypes and poor mimics [1-4], we identified multiple examples of intraspecific polymorphism and a high number of different aposematic patterns in a single community. Further detailed research should be focused on the role of factors that can relax or slow the effects of purifying selection, e.g., the generalization of multiple patterns by predators, evolutionary constraints such as the ability, or inability, to rapidly adopt the dominant local aposematic pattern $[3,7,16,39]$ and here suggested behavioral adaptation and variable perception of the body shape and colour (compare
Fig. 1a, c, e, g with b, d, f, h showing perception of insect individuals against clear sky and the same individuals illuminated by an artificial light source).

\section{Eniclases communities in space and time}

The model of Müllerian mimicry is simple and earlier experiments have not considered fluctuating conditions during the process of convergence or advergence. Based on our observations, we must assume that the communities in which Eniclases occur dynamically change in space due to local conditions and across the altitudinal gradient (Table 1). As a result migrating Eniclases commonly enter different mimetic complexes. While we found that similar communities can be expected at similar altitudes in New Guinea, we observed a distinct community composition in the Dombomi locality, which does not contain brightly colored trichalines despite being located at a low elevation. Dombomi is situated on the windward slope of a high mountain range and differs from Elelim in having high levels of precipitation and fog, which supports dense, marshy, medium-height forests with a different fauna. It means that communities with different species and pattern composition might not necessarily be geographically distant.

Additionally, we identified substantial altitude dependent differences in species composition. Despite a distance of less than $2 \mathrm{~km}$, Bokondini communities sampled from 1250 and $1850 \mathrm{~m}$ in elevation shared no common species (richness of 26 and 58 species, respectively). Although netwinged beetles are poor dispersers, even low levels of continuous migration could increase the number of aposematic patterns in a community, delay pattern convergence, and increase the number of color-polymorphic species simultaneously adverging to different models [16]. Further research should consider that the communities we analyze today may be products of very different histories, particularly concerning migration.

\section{Conclusion}

Eniclases species are uniform in the body size and shape and unrelated species share similar color patterns. In accordance with the explanation of the phenetic uniformity of other unpalatable aposematically coloured insects, we hypothesize that observed similarity of various Eniclases was produced by natural selection [1-4], not by common ancestry. Therefore, we considered the diversity of aposematic signals, polymorphism, and coexistence of various patterns within single communities or aggregations of unprofitable net-winged beetles. We suggest that multiple color patterns in net-winged beetles may persist in single communities (1) due to the presence of species that are not able to readily adopt the dominant color pattern (i.e., we observed the absence of red pigment and metallic colours in over 200 species of 
Eniclases, and closely related Microtrichalus, Trichalus, Lobatang, and Schizotrichalus [16]) and (2) due to limited perception of colour patterns by predators under some conditions (Figs. 1a-h). Further, we suggest the likelihood of limited, but continuous migration of individuals among populations with different species compositions and pattern frequencies. This hypothesis is based on observed high species turnover between geographically close communities and the presence of a large number of species in communities. As a result of such migration, the number of patterns in the local community would remain continually high and populations or species displaying low-contrast patterns and intraspecific polymorphism could persist for a longer time than in monomorphic Müllerian communities [40]. As we did not perform any experiments under controlled conditions, we cannot conclude if hypothesized selection against rare phenotypes is merely relaxed [41] or is inherently unable to exclude differently colored individuals from complex communities such as those described here. Müllerian mimicry within net-winged beetles is rarely studied, and here we show the potential of Lycidae as an ecologically interesting and highly diverse mimetic lineage.

\section{Methods}

\section{Field sampling and Eniclases specimens}

We collected specimens of 12 Eniclases species from seven localities within a small study area $\left(\sim 1300 \mathrm{~km}^{2}\right)$ in central New Guinea in localities at the northern coast, across an elevation range from sea level to $2170 \mathrm{~m}$ (Additional file 1: Tables S1, S3). The majority of individuals were collected in aggregations, designated AGG1-Sentani (275 m), AGG2-Elelim (560 m), AGG3Bokondini1 (1287 m), and AGG4-Bokondini2 (1250$1300 \mathrm{~m}$ ). Additional specimens were collected individually in areas with low net-winged beetle abundance. Coloration of the pronotum and elytra were recorded, and patterns were grouped into eight discrete categories (Table 1). All photographs of specimens are provided in Additional file 1: Figures S1-S4.

\section{Colour pattern classification}

Color patterns of New Guinean Eniclases were classified into eight categories: (a) uniform black; (b) pronotum orange, elytra black, (c) pronotum and humeral patches orange, remainder of elytra black; (d) pronotum and humeral part of elytra orange, remainder of elytra black; (e) pronotum black, humeral part of elytra orange, remainder of elytra black; (f) pronotum black, the humeral part of elytra light yellow, apex infuscate; (g) pronotum and elytra orange to light yellow, the apex of elytra infuscate, and; (h) uniform yellow.

\section{Laboratory procedures}

Total DNA was extracted using a Wizard SV96 Purification System (Promega Inc.). Extraction yields were measured using a NanoDrop-1000 Spectrophotometer. The fragments $r r n L+t R N A-L e u+n a d 1(\sim 830 \mathrm{bp})$ and nad5 + tRNAs $(\sim 1210 \mathrm{bp})$ mitochondrial DNA (mtDNA) were amplified. Primers are listed in Additional file 1: Table S2 and polymerase chain reaction (PCR) settings followed Sklenarova et al. [21]. PCR products were purified using PCR $\mu$ 96TM Plates (Millipore Inc.) and sequenced by an ABI3130 automated sequencer using a BigDye ${ }^{\circ}$ Terminator Cycle Sequencing Kit 1.1. Sequences were deposited in the GenBank database (accession numbers KT265092KT265172, MF288197-MF288482 and MG844591MF844955).

\section{MtDNA data sampling and phylogenetic analyses}

Earlier published sequences of cox1 mtDNA [42] were merged with $r r n L$ and nad5 fragments. Fragments were aligned separately using MAFFT v. 7.017 [43] in Geneious 7.1.9 (Biomatters, Ltd., Auckland, New Zealand) and the concatenated dataset was analyzed to infer a phylogenetic tree. We used IQ-TREE v. 1.6.6 [44] to estimate mtDNA phylogeny using an ultrafast bootstrap approximation and 5000 iterations. The best models for each fragment were selected in IQ-TREE using ModelFinder [45] (Additional file 1: Table S3).

A tree pruned to one representative per species was dated using a Bayesian approach implemented in BEAST 1.8.1 [46]. We produced $5 \times 10^{7}$ generations with sampling every 2500 generations. Only the $r r n L$, coxl, and nad5 genes were analyzed and genes and codon positions were partitioned (Additional file 1: Table S3). Each partition was provided with its own parameters. Due to an absent fossil record and young relevant splits, i.e., younger than five million years, we used mtDNA rate information to calibrate our topology: 0.0115 subs/ s/my/l for cox 1, $0.0177 \mathrm{subs} / \mathrm{s} / \mathrm{my} / \mathrm{l}$ for $n a d 5$, and 0.0054 subs/s/my/l for $r r n L$ [47]. To estimate the possible effects of a higher rate of mutations, we repeated the analyses of the cox 1 fragment with a doubled rate $(0.023$ subs/s/my/l). The best topology recovered from maximum likelihood analyses was fixed by a guiding tree and switching off tree operators during analyses. Convergence was assessed in Tracer v. 1.7 [48] and the first $1.25 \times 10^{7}$ generations were set as a burn-in.

\section{Next-RAD sampling and analyses}

Based on the mtDNA analyses, we selected 66 individuals for subsequent RAD sequencing. The samples represent 14 species of Eniclases net-winged beetles from seven sites. We used a high number of genomic loci across closely related species and populations as they could provide resolution on recent species-level interactions and 
support the phylogenetic hypothesis $[49,50]$. Given that a reference genome is unavailable for RAD data masking due to its size (3-5 GB), de novo assembly with clustering thresholds (Wclust, degree of sequence similarity) was used to search for orthologous sequences [51]. The nextRAD genomic sequencing was provided by SNPsaurus Inc., where the Illumina $\mathrm{Hi}$-Seq system was used to generate data. The DNA next to a restriction site GTGTAGAGG was sequenced. RAD sequencing produces individually barcoded single-end read amplifications with an average length of $\sim 75 \mathrm{bp}$ representing loci scattered across the genome. Each read was individually assigned to the specific specimen voucher. Illumina reads were deposited in the Sequence Read Archive (PRJNA544184).

Quality of raw Illumina reads were visualized by FastQC. We used the software iPYRAD 0.6.24 [52] to de-multiplex, trim, filter and identify a de novo assembly of orthologous loci. This software uses an alignmentclustering method involving indel variation, which improves the precision of recognition of global homology across different samples, and read trimming, which generates variable read lengths unlike alternative assembly methods, e.g., Stacks $[53,54]$. First, all Illumina adapters were removed from data. The data were processed for all individuals with separate identifiers and the reads without identifier were excluded. Then, bases were trimmed from the $3^{\prime}$ end of reads when the quality score was below 30 . The minimum depth for the base call was set to 6. Other parameters were set to default values.

The maximum size of the data matrix varied as we varied the Wclust parameter. We tested these matrices by analyzing five Wclust settings from $0.7-0.9$, increasing by 0.05 for each filtering. The number of potential loci increased when Wclust increased, although within-individual heterozygosity decreased significantly when Wclust was set higher than 0.85 (Additional file 1: Figure S5). To balance the highest proportion of potential loci accepted and the highest rate of sample heterozygosity, a Wclust value of 0.85 was used in the final analyses. A minimum depth (MinDepth) of six reads, together with a minimum number of four samples that contained data for a given locus (minimum taxon coverage, MinCov) was used in the final dataset whose analysis was used for discussion. The proportion of missing data and the number of loci filtered may affect the recovered topology. These characteristics are strongly dependent on the MinCov parameter [55], therefore, we also produced additional data matrices with varied MinCov and Wclust values. Altogether, 30 datasets with unique settings were generated (Wclust from $0.7-0.9$ increasing by 0.05 and MinCov of 4, 8, 16, 33, 48 and 60 for each unique filtering). To test the congruence of topologies within individual clades of closely related species, data were filtered independently for clades $\mathrm{A}$ through $\mathrm{C}$, as defined by preliminary analyses. We inferred individual admixture coefficients based on sparse non-negative matrix factorization (sNMF) analyses using the package 'LEA' in R [56] on a dataset with a Wclust of 0.85 and a MinCov of 4 to reveal population genetic structure. We evaluated cross-entropy criterion for clusters $\mathrm{K}=1-10$ using the obj.snmf function in LEA [56]. We further performed principal components analysis (PCA) in R, using the package 'SNPRelate' 1.6.4 [57] to visualize the major axes of genetic variation using the above dataset, reduced by linkage-disequilibrium-based single nucleotide polymorphism (SNP) pruning as implemented in the package 'SNPRelate', the command snpgdsLDpruning and ld.threshold $=0.1$.

Each matrix generated with a specific Wclust and MinCov values was used to infer a maximum likelihood phylogenetic tree using same settings as described above. We analyzed them with a maximum likelihood approach using IQ-TREE, with an ultrafast bootstrap approximation and 5000 iterations. ModelFinder, implemented in IQ-TREE, estimated the optional evolution model for final matrix (Additional file 1: Table S3). Resulting tree topologies from all data matrices were examined and are provided in the Additional file 2 "The resulting tree topologies from all data matrices recovered from RAD data filtering". In addition to maximum likelihood trees inferred using IQ-TREE, we used SVDquartets [58], implemented in PAUP* (v. 4.0a, build 165 [59];), and evaluated bootstrap support over 1000 iterations. In the final step, the PAUP** version of the QFM algorithm [60] was used to search for the overall tree that minimized the number of quartets that were inconsistent with it. All produced topologies were checked to identify possible incongruences.

\section{Additional files}

Additional file 1: Table S1. The list of samples with information on geographic origins and color patterns. Table S2. Primers used for mtDNA amplification. Table S3. Characteristics of datasets and best-fit models for mtDNA and nextRAD partitions. Table S4 Measurements of Eniclases. Table S5. Euclidian distances among sampled localities in central New Guinea. Table S6. The species structure of Metriorrhynchina communities. Figures S1-S4. Aposematic patterns of sequenced specimens from northern New Guinea (parts 1-4). Figure S5. Testing of the effect of clustering threshold on individual heterozygosity and proportion of loci generated. Figure S6. The full resolution RAD-based tree. Figure S7. The full resolution RAD-based analyses of individual subclades based on subset read filtering. Figure S8. The dated tree based on mtDNA dataset. Figure S9. Principal component analysis of three defined clades A, B and C based on RAD dataset. Figures S10-S14. Plots of individual's admixture coefficients based on sparse non-negative matrix factorization (sNMF) implemented in R package LEA for the specific clades.

Additional file 2: The resulting tree topologies from all data matrices recovered from RAD data filtering. The trees are provided in the newick format. 


\section{Abbreviations}

AGG: Aggregation; DNA: Deoxyribonucleic acid; MinCov: Minimal coverage; MinDepth: Minimum depth; PCA: Principal component analysis; PCR: Polymerase chain reaction; RAD: Restriction site associated DNA markers; SNMF: sparse non-negative matrix factorization; Wclust: clustering threshold as a decimal number

\section{Acknowledgements}

We thank colleagues who provided some samples for this study and R. Bilkova for technical assistance.

\section{Authors' contributions}

$L B$ designed the project, $M B, D K$ and $M M$ analyzed data, $M B$ and $L B$ wrote the manuscript; $L B$ contributed materials and resources. All authors contributed to the final manuscript.

\section{Funding}

This study was supported by GACR project (18-14942S) to M.B., M.M., D.K. and L.B.

\section{Availability of data and materials}

Sequence data can be found NCBI Sequence Read Archive (SRA; ABCDE111111) and GenBank (mtDNA data, KT265092-KT265172, MF288197-MF288482 MG844591-MF844955)

\section{Ethics approval and consent to participate}

Not applicable.

\section{Consent for publication}

Not applicable.

\section{Competing interests}

The authors declare that they have no competing interests.

\section{Received: 5 June 2019 Accepted: 28 August 2019}

\section{Published online: 17 October 2019}

\section{References}

1. Mallet J, Barton NH. Strong natural selection in a warning colour hybrid zone. Evolution. 1989;43:421-31. https://doi.org/10.1111/j.1558-5646.1989. tb04237.x.

2. Sherratt TN. The evolution of Müllerian mimicry. Naturwissenschaften. 2008; 95:681-95. https://doi.org/10.1007/s00114-008-0403-y.

3. Kikuchi DW, Pfennig DW. Imperfect mimicry and the limits of natural selection. Q Rev Biol. 2013;88:297-315. https://doi.org/10.1086/673758.

4. Mallet J, Joron M. Evolution of diversity in warning color and mimicry: polymorphisms, shifting balance and speciation. Ann Rev Ecol Syst. 1999;30: 201-33. https://doi.org/10.1146/annurev.ecolsys.30.1.201.

5. Mappes J, Marples N, Endler JA. The complex business of survival by aposematism. Trends Ecol Evol. 2005;20:598-603. https://doi.org/10.1016/j. tree.2005.07.011.

6. Chouteau M, Arias M, Joron M. Warning signals are under positive frequency-dependent selection in nature. Proc Natl Acad Sci U S A. 2016; 113:2164-9. https://doi.org/10.1073/pnas.1519216113.

7. Edmunds M. Why there are good and poor mimics? Biol J Linn Soc 2000;70:459-66. https://doi.org/10.1111/j.1095-8312.2000.tb01234.x.

8. Penney HD, Hassall C, Skevington JH, Abbott KR, Sherratt TN. A comparative analysis of the evolution of imperfect mimicry. Nature. 2012;483:461-4 https://doi.org/10.1038/nature10961.

9. Speed MP, Ruxton GD. Imperfect Batesian mimicry and the conspicuousness costs of mimetic resemblance. Amer Nat. 2004;176:E1-E14. https://doi.org/10.1086/652990.

10. Briolat ES, Burdfield-Steel ER, Paul SC, Ronka KH, Seymoure BM, Stankowich T, Stuckert AMM. Diversity in warning coloration: selective paradox or the norm? Biol Rev. 2019;94:388-414. https://doi.org/10.1111/brv.12460.

11. Beatty CD, Beirinckx K, Sherratt TN. The evolution of Müllerian mimicry in multispecies communities. Nature. 2004;431:63-7. https://doi.org/10.1038/ nature02818.

12. Skelhorn J, Holmes GG, Hossie TJ, Sherratt TN. Multicomponent deceptive signals reduce the speed at which predators learn that prey are profitable. Behav Ecol. 2016;27:141-7. https://doi.org/10.1093/beheco/arv135.
13. Speed MP. Müllerian mimicry and the psychology of predation. Anim Behav. 1993:45:571-80. https://doi.org/10.1006/anbe.1993.1067.

14. Sherratt TN, Peet-Paré CA. The perfection of mimicry: an information approach. Phil Trans R Soc - Biol Sci. 2017;372:20160340. https://doi.org/10. 1098/rstb.2016.0340

15. Arenas LM, Troscianko J, Stevens M. Color contrast and stability as key elements for effective warning signals. Front Ecol Evol. 2014;2:25. https://doi. org/10.3389/fevo.2014.00025

16. Motyka M, Kampova L, Bocak L. Phylogeny and evolution of Müllerian mimicry in aposematic Dilophotes: evidence for advergence and sizeconstraints in evolution of mimetic sexual dimorphism. Sci Rep. 2018;8:3744 https://doi.org/10.1038/s41598-018-22155-6.

17. Jiruskova A, Motyka M, Bocek M, Bocak L. The Malacca Strait separates distinct faunas of poorly-flying Cautires net-winged beetles. PeerJ. 2019;7:e6511. https://doi.org/10.7717/peeri.6511.

18. Linsley EG, Eisner T, Klots AB. Mimetic assemblages of sibling species of lycid beetles. Evolution. 1961;15:15-29. https://doi.org/10.2307/2405840.

19. Moore BP, Brown WV. Identification of warning odor components, bitte principles and antifeedants in an aposematic beetle - Metriorrhynchus rhipidius (Coleoptera: Lycidae). Ins Biochem. 1981;11:493-9. https://doi.org/ 10.1016/0020-1790(81)90016-0.

20. Eisner T, Schroeder FC, Snyder N, Grant JB, Aneshansley DJ, Utterback D, et al. Defensive chemistry of lycid beetles and of mimetic cerambycid beetles that feed on them. Chemoecology. 2008;18:109-19. https://doi.org/ 10.1007/s00049-007-0398-4.

21. Sklenarova K, Kubecek V, Bocak L. Subtribal classification of Metriorrhynchini (Insecta: Coleoptera: Lycidae): an integrative approach using molecular phylogeny and morphology of adults and larvae. Arthropod Syst Phyl. 2014;72:37-54. https://doi.org/10.1371/journal.pone.0067957.

22. Bocek M, Bocak $L$. The molecular phylogeny and classification of trichaline net-winged beetles (Lycidae: Metriorrhynchini). PeerJ. 2017;5:e3963. https:// doi.org/10.7717/peerj.3963.

23. Bocek M, Bocak $L$. The origins and dispersal history of the trichaline netwinged beetles in South East Asia, Wallacea, New Guinea and Australia. Zool 」 Linnean Soc. 2019;185:1079-94. https://doi.org/10.1093/zoolinnean/zly090.

24. Kalousova R, Bocak L. Species delimitation of colour polymorphic Cladophorus (Coleoptera: Lycidae) from New Guinea. Zootaxa. 2017;4320: 505-22. https://doi.org/10.11646/zootaxa.4320.3.6.

25. Nadeau N. Butterfly genomics sheds light on the process of hybrid speciation. Mol Ecol. 2014:23:4441-3. https://doi.org/10.1111/mec.12877.

26. Fabricant SA, Herberstein ME. Hidden in plain orange: aposematic coloration is cryptic to a colourblind insect predator. Behav Ecol. 2015;26:38-44. https://doi.org/10.1093/beheco/aru157.

27. Michie $\sqcup$, Mallard F, Majerus MEN, Jiggins FM. Melanic through nature or nurture: genetic polymorphism and phenotypic plasticity in Harmonia axyridis. J Evol Biol. 2010;23:1699-707. https://doi.org/10.1111/j.1420-9101.2010.02043.

28. Stuckert AMM, Venegas PJ, Summers K. Experimental evidence for predator learning and Müllerian mimicry in Peruvian poison frogs (Ranitomeya, Dendrobatidae). Evol Ecol. 2014:28:413-26. https://doi.org/10.1007/s10682-013-9685-4.

29. Bocak L, Yagi T. Evolution of mimicry patterns in Metriorrhynchus (Coleoptera: Lycidae): the history of dispersal and speciation in Southeast Asia. Evolution. 2010;64:39-52. https://doi.org/10.1111/j.1558-5646.2009.00812.x.

30. Leache AD, Oaks JR. The utility of single nucleotide polymorphism (SNP) data in phylogenetics. Ann Rev Ecol Syst. 2017;48:69-84. https://doi.org/10. 1146/annurev-ecolsys-110316-022645.

31. Willmott KR, Willmott JCR, Elias M, Jiggins CD. Maintaining mimicry diversity: optimal warning color patterns differ among microhabitats in Amazonian clearwing butterflies. Proc R Soc - Biol Sci 2017;284, 20170744. https://doi. org/10.1098/rspb. 2017.0744.

32. Raska J, Stys P, Exnerova A. How variation in prey aposematic signals affects avoidance learning, generalization and memory of a salticid spider. Anim Behav. 2017;130:107-17. https://doi.org/10.1016/j.anbehav.2017.06.012

33. Roper TJ, Redston S. Conspicuousness of distasteful prey affects the strength and durability of one-trial avoidance-learning. Anim Behav. 1987; 35:739-47. https://doi.org/10.1016/S0003-3472(87)80110-0.

34. Rowe $C$, Lindström $L$, Lyytinen $A$. The importance of pattern similarity between Müllerian mimics in predator avoidance learning. Proc R Soc - Bio Sci. 2004:271:407-13. https://doi.org/10.1098/rspb.2003.2615.

35. Aronsson M, Gamberale-Stille G. Importance of internal pattern contrast and contrast against the background in aposematic signals. Behav Ecol. 2009;20:1356-62. https://doi.org/10.1093/beheco/arp141. 
36. Gagliardo A, Guilford T. Why do warning-colored prey live gregariously. Proc R Soc - Biol Sci. 1993;251:69-74. https://doi.org/10.1098/rspb.1993.0010.

37. O'Hanlon JC. The roles of color and shape in pollinator deception in the orchid mantis Hymenopus coronatus. Ethology. 2014;120:652-61. https:// doi.org/10.1111/eth.12238.

38. Kazemi B, Gamberale-Stille G, Tullberg BS, Leimar O. Stimulus salience as an explanation for imperfect mimicry. Curr Biol. 2014;24:965-9. https://doi.org/ 10.1016/j.cub.2014.02.061

39. Johnstone RA. The evolution of inaccurate mimics. Nature. 2002;418:524-6. https://doi.org/10.1038/nature00845.

40. Cuthill IC, Allen WL, Arbuckle K, Caspers B, Chaplin G, Hauber ME, et al. The biology of color. Science. 2017;357:470-3. https://doi.org/10.1126/science. aan0221.

41. Wilson JS, Jahner JP, Williams KA, Forister ML. Ecological and evolutionary processes drive the origin and maintenance of imperfect mimicry. PLoS One. 2013;8:e61610. https://doi.org/10.1371/journal.pone.0061610.

42. Bocek $M$, Bocak $L$. Species limits in polymorphic mimetic Eniclases netwinged beetles from new Guinean mountains (Coleoptera: Lycidae). ZooKeys. 2016:593:15-35. https://doi.org/10.3897/zookeys.593.7728.

43. Katoh K, Standley DM. MAFFT multiple sequence alignment software version 7: improvements in performance and usability. Mol Biol Evol. 2013;30:772-80. https://doi.org/10.1093/molbev/mst010.

44. Nguyen LT, Schmidt HA, Von Haeseler A, Minh BQ. IQ-TREE: a fast and effective stochastic algorithm for estimating maximum-likelihood phylogenies. Mol Biol Evol. 2015;32:268-74. https://doi.org/10.1111/j.14209101.2010.02043.

45. Kalyaanamoorthy S, Minh BQ, Wong TKF, Von Haeseler A, Jermiin LS. ModelFinder: fast model selection for accurate phylogenetic estimates. Nature Meth. 2017;14:587-9. https://doi.org/10.1038/nmeth.4285.

46. Drummond AJ, Suchard MA, Xie D, Rambaut A. Bayesian phylogenetics with BEAUti and the BEAST 1.7. Mol Biol Evol. 2012;29:1969-73. https://doi.org/10. 1093/molbev/mss075

47. Papadopoulou A, Anastasiou I, Vogler AP. Revisiting the insect mitochondrial molecular clock: the mid-Aegean trench calibration. Mol Biol Evol. 2010;27:1659-72. https://doi.org/10.1093/molbev/msq051.

48. Rambaut A, Drummond AJ, Xie D, Baele G, Suchard MA. Posterior summarisation in Bayesian phylogenetics using tracer 1.7. Syst Biol. 2018;67:901-4. https://doi.org/10.1093/sysbio/syy032.

49. Bray TC, Bocak L. Slowly dispersing neotenic beetles can speciate on a penny coin and generate space-limited diversity in the tropical mountains. Sci Rep. 2016;6:33579. https://doi.org/10.1038/srep33579.

50. Lavretsky P, Da Costa JM, Sorenson MD, Mc Cracken KG, Peters JL. ddRAD-seq data reveal significant genome-wide population structure and divergent genomic regions that distinguish the mallard and close relatives in North America. Mol Ecol. 2019; in press. https://doi.org/10.1111/mec.15091.

51. Ekblom R, Galindo J. Applications of next generation sequencing in molecular ecology of non-model organisms. Heredity. 2011;107:1-15. https://doi.org/10.1038/hdy.2010.152.

52. Eaton DAR, Overcast I. iPYRAD: interactive assembly and analysis of RADseq data sets. 2016; Retrieved from https://ipyrad.readthedocs.io/

53. Catchen JM, Amores A, Hohenlohe P, Cresko W, Postlethwait JH. Stacks: building and genotyping loci de novo from short-read sequences. G3: Genes Genom Genet. 2011;1:171-82. https://doi.org/10.1534/g3.111.000240.

54. Takahashi T, Nagata N, Sota T. Application of RAD-based phylogenetics to complex relationships among variously related taxa in a species flock. Mol Phyl Evol. 2014;80:77-81. https://doi.org/10.1016/j.ympev.2014.07.01.

55. Huang $\mathrm{H}$, Knowles LL. Unforeseen consequences of excluding missing data from next-generation sequences: simulation study of RAD sequences. Syst Biol. 2016;65:357-65. https://doi.org/10.1093/sysbio/syu046.

56. Frichot $\mathrm{E}$, François O. LEA: an R package for landscape and ecological association studies. Methods Ecol Evol. 2015;6:925-9. https://doi.org/10. 1111/2041-210X.12382.

57. Zheng X, Levine D, Shen J, Gogarten SM, Laurie C, Weir BS. A highperformance computing toolset for relatedness and principal component analysis of SNP data. Bioinformatics. 2012;28:3326-32. https://doi.org/10. 1093/bioinformatics/bts606.

58. Chifman J, Kubatko L. Quartet inference from SNP data under the coalescent model. Bioinformatics. 2014;30:3317-24. https://doi.org/10.1093/ bioinformatics/btu530.

59. Swofford DL. PAUP* Phylogenetic Analysis using Parsimony (and Other Methods). 2002; Sinauer associates, Sunderland, MA.
60. Reaz R, Bayzid MS, Rahman MS. Accurate phylogenetic tree reconstruction from quartets: a heuristic approach. PLoS One. 2014;9:e104008. https://doi. org/10.1371/journal.pone.0104008.

\section{Publisher's Note}

Springer Nature remains neutral with regard to jurisdictional claims in published maps and institutional affiliations.
Ready to submit your research? Choose BMC and benefit from:

- fast, convenient online submission

- thorough peer review by experienced researchers in your field

- rapid publication on acceptance

- support for research data, including large and complex data types

- gold Open Access which fosters wider collaboration and increased citations

- maximum visibility for your research: over $100 \mathrm{M}$ website views per year

At BMC, research is always in progress.

Learn more biomedcentral.com/submissions 